\title{
Developing Student's German Language Competencies through Pragmatic Approach in the Classroom for Higher Education
}

\author{
Rina Evianty ${ }^{1}$, Risnovita Sari ${ }^{2}$, Muhammad Reza ${ }^{3}$ \\ ${ }^{1,2,3}$ Universitas Negeri Medan, Indonesia \\ rina.frau@yahoo.com
}

\section{Abstract}

The general goal of teaching German as a foreign language is that learners can communicate appropriately in writing and orally in German. But in fact this goal can often not be achieved. Many learners in higher education master the German grammar and vocabulary, but they are unable to use German language that matches the social context, because they do not have much pragmatics competence. Pragmatic approach based on the function of language as a communication tool is a study of language by involving various aspects outside the language that are able to provide meaning. Pragmatic competence constitutes a significant factor in determining the success of communication. In fact, a German language learner in higher education is not only expected to use language and produce utterances which are understandable or grammatically correct, but is also expected to produce utterances which are socioculturally appropriate. However, for students in higher education who learn German as a Foreign Language (Deutsch als Fremdsprache/DaF), the pragmatic competence, which can actually be acquired naturally through social interaction, is quite difficult to acquire due to the limited. On this basis, pragmatics needs to be integrated into German language courses in higher education, which includes pragma linguistics and socio pragmatic. In this regard, this study describes not only the relationship between pragmatics and German as a foreign language, but also this study is an attempt to define its implications in teaching German as foreign language in higher education.

\section{Keywords}

teaching; German as a foreign language (Deutsch als Fremdsprache/DaF) in higher education; pragmatics; pragmatics competence

\section{Introduction}

Pragmatics is a part of linguistics that can be defined as a study of communicative acts in a sociocultural context (Kasper, 1997). Thomas (1995: 23) suggested that pragmatics is meaning in interaction, because it takes into account the different contributions of the speaker and listener, as well as the utterance and context, in order to make sense. Currently pragmatics plays an important role in language teaching. Granger (by Bardovi-Harlig, 2005) said,

Pragmatics has become a major field of study in its own right, in linguistics, and now in language learning and teaching. Pragmatic competence has come to be viewed as an essential part of learners' competence.

According to this opinion, pragmatic competence is an important aspect of language teaching that has to be taken into account. It often happens that learners who have a good command of the grammar and vocabulary of the target language, but cannot communicate properly in the target language. Their expressions are often inappropriate to the linguistic 
context. One possible cause, which is often mentioned, is that pragmatics is not taken into account in the teaching of the target language or even not treated.

For this reason, the following aspects are described in this paper: (1) the background of why pragmatics should be integrated into language teaching, (2) pragmatic competence and the goal of pragmatics teaching, (3) pragmatic teaching materials, and (4) how pragmatic aspects are used can be.

\section{Research Methods}

This paper discusses literature review as a methodology research. A literature review or narrative review is a type of review article. A literature review is a scholarly paper, which includes the current knowledge including substantive findings, as well as theoretical and methodological contributions to a particular topic. Literature reviews are secondary sources, and do not report new or original experimental work. Most often associated with academicoriented literature, such reviews are found in academic journals, and are not to be confused with book reviews that may also appear in the same publication. Literature reviews are a basis for research in nearly every academic field. A narrow-scope literature review may be included as part of a peer-reviewed journal article presenting new research, serving to situate the current study within the body of the relevant literature and to provide context for the reader. In such a case, the review usually precedes the methodology and results sections of the work.

\section{Discussion}

\subsection{The Historical Background of the Introduction of Pragmatics in the Language Teaching}

In order to know more exactly when the pragmatics competence emerged as an inseparable part of language teaching or foreign language teaching, one can follow the development of teaching methods. From the 19th century to the beginning of the 20th century, language teaching was dominated by the grammatical translation method. This method emphasizes the recognition of the sense of language and the mastery of grammar. Over time, the direct method appeared as the opposite of the previous methods. According to this method, mastery of the oral language is most important. The learners deal directly with the sounds of the target language, and new words are not translated explained, rather by statement in the target language or by visual Media.

The grammar of the target language is not taught deductively, as in the previous method (Purwo, 1990: 44-45). Before World War II a new teaching method was known, namely "Audiolingual Method". This method is clearly influenced by Bloomfield's structuralist linguistics and Skinner's theory of stimulus and response. In the classroom, learners are continuously trained with the listening exercises and follow-up of the pattern patterns (drill and pattern practice ), so that the trained sentence patterns are fixed in the mind of the learner and become a habit.

In 1965, Noam Chomsky criticized the behaviorist model in language acquisition. He said that language learning is not the habit, but rather a creative process: a rationalistic and cognitive activity, not the effect of the response from the external stimulus (Purwo, 1990: 47). Afterwards Chomsky introduced two concepts, namely competence (language ability) and performance (language use). Within the framework of language learning, the formation 
of competence is very important. In this case, the teachers should raise the learners' awareness of the rules of the target language.

The previously mentioned methods and paradigms actually have the same characteristics, namely that the language structure is always in the foreground and that these methods do not take into account sociocultural aspects of the opportunity to speak. The first criticism came from Dell Hymes. He said that there are rules in linguistic usage, without them the language structure is nonsense. That is, in language teaching grammaticality is no longer in the foreground. An even more important consideration is the appropriateness of an utterance in its sociocultural context. Halliday was also on the side of Hymes. He rejected the dichotomy between competence and performance. In his opinion, Chomsky's competence covers only "what the speaker knows" and not "what the speaker can do with it" (Purwo, 1990: 49). The criticism of Hymes and Halliday then leads to the emergence of the communicative approach in language teaching or foreign language teaching.

Communicative approach (Richards \& Schmidt, 2002) is:

On approach to foreign or second language teaching emphasizes which did the goal of language learning is communicative competence and which seeks to make meaningful communication and language use a focus of all classroom activities.

From this opinion one can see clearly that the main goal of the communicative approach is to achieve the communicative competence. Canale and Swain (1980) then identify the sub-aspects of communicative competence (see Figure 1). The communicative competence consists of grammatical, sociolinguistic and strategic competence. Thus, one can say that the communicative approach already takes into account the sociocultural aspect, which has not been mentioned in previous methods and paradigms.

\begin{tabular}{|c|c|c|c|}
\hline \multicolumn{4}{|c|}{ Communicative Competence (Canale and Swain, 1980) } \\
\hline \multirow[b]{2}{*}{$\begin{array}{l}\text { Grammatical Competence } \\
\text { ( knowledge of } \\
\text { lexical items and of } \\
\text { rules of morphology, } \\
\text { syntax, sentence- } \\
\text { grammar semantics, } \\
\text { and phonology) }\end{array}$} & \multicolumn{2}{|c|}{ Sociolinguistic Competence } & \multirow[b]{2}{*}{$\begin{array}{c}\text { Strategic Competence } \\
\text { (verbal and non-verbal } \\
\text { communication strategies that may } \\
\text { or may not be understood) }\end{array}$} \\
\hline & $\begin{array}{c}\text { sociocultural } \\
\text { Competence } \\
\text { (knowledge } \\
\text { of the } \\
\text { relationship } \\
\text { of language } \\
\text { use to its } \\
\text { non- } \\
\text { linguistic } \\
\text { context) }\end{array}$ & $\begin{array}{c}\text { Discourse } \\
\text { Competence } \\
\text { (knowledge of } \\
\text { rules } \\
\text { governing } \\
\text { cohesion and } \\
\text { coherence) }\end{array}$ & \\
\hline
\end{tabular}

(Source: http://www.auburn.edu/ nunnath/engl6240/clt.html)

Figure 1. Aspects of communicative competence

The term pragmatics first appeared in language proficiency - a model of Bachman, which is actually another modification of Canale and Swain's model. Bachmann divided this language competence into two major parts, namely organizational competence and pragmatic competence. The organizational competence is the knowledge of linguistic units and the rules 
of how to arrange these units in the sentences (called grammatical competence) and in the texts (textual competence). The pragmatic competence consists of illocutionary competence and sosiolinguistischer Competence. The first is the Knowledge over communication act and how it is then realized in reality. The second is the ability to use the language appropriately with the context (Kasper, 1997).

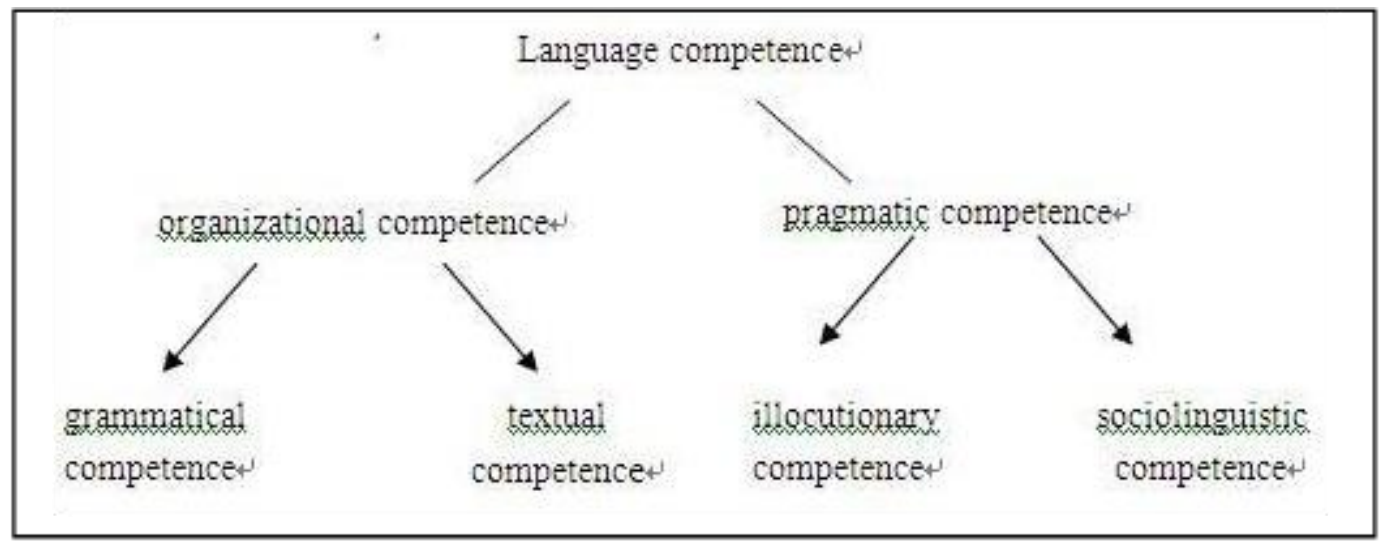

(Source: http://foreign.jiangnan.edu.cn/yyzx/Detail.aspx?uid=94)

Figure 2. Language skills of Bachmann

Based on the Bachmann model one learns that pragmatics competence is just as important as grammatical competence, which is previously considered a lot by language teachers. It is also clear from this model that comprehensive language comprehension consists of two components - namely organizational and pragmatic competence. Nevertheless, there is still a question as to whether pragmatic competence should be used in language teaching? The reasons for this are the following, firstly, some believe that the pragmatic competence can be achieved automatically once the organizational competence has been achieved. But this is not always the case because good grammatical and lexical mastery is not the basis for achieving good pragmatics competence. Boxer and Pickering (by Salemi, Rabiee, and Ketabi, 2012) said that learners who are good at grammar may not know how to use the language adequately in the different situations. They often translate direct speech acts of the first language in the target language than they would like to express their opinions / ideas. Direct translation could cause pragmatic mistakes. These pragmatic mistakes are often disregarded by the teachers, compared to the grammatical ones Errors.

Second, some also believe that aspects of pragmatics are universal. If one learns second language (foreign language), one actually already keeps the pragmatic aspects in his first language (native language), such as indirect or direct speech,

Knowledge on social and psychological distance in communication, use of communication strategies, and speech acts. The pragmatic competence in the first language is then normally transferred to the target language when the learners communicate in target language. It would be easy, as long as this transfer is positive, especially if the cultural background of the first and second language has almost the same characteristics. Otherwise, the negative transfer will be the highest possible and this can potentially lead to pragmatic mistakes. Bardovi-Harlig (by Chen, 2009) said that a speaker whose speech is pragmatically incorrect does not look cooperative, even rude or mocking. For this reason, it can once again 
be emphasized that the learners should be taught to have good pragmatic competence to reach.

\subsection{Pragmatic Competence and Goal of the Pragmatics Teaching}

Taguchi (2011: 289-291) defines pragmatic competence as the ability to communicate and interpret meaning in the social context. This competence includes the ability to manage a complex interaction among language, voice user, and context of interaction. Taguchi's opinion shows us that pragmatic competence is a complex thing. Therefore, it is not so easy to create a lesson program in which learners can achieve pragmatic competence. The teacher should understand and treat two aspects of pragmatics correctly, namely pragmalinguistics and sociopragmatics (Brown \& Levinson in Tan and Farashaiyan, 2012: 1889).

Pragmalinguistics refers to the knowledge of the linguistic units that one can use to create communication or to realize certain speech acts. Pragmalinguistics also includes pragmatic strategies, such as direct or indirect, routine formalities, and linguistic forms that can reinforce or refine a communicative action. The second component, sociopragmatics, is described by Leech (via Kasper, 1997) as the " sociological interface of pragmatics". This refers to the ability of the speaker or listener to judge the context. For example, if a learner wishes to compliment the target language, he or she should for the first time properly understand the situation and then select linguistic forms that are most appropriate given the social relationship between the speaker and the listener. These both components must be taken into account if you want to plan and design a pragmatics lesson.

The main objective of a pragmatics class is to sensitize (increase) the pragmatic awareness of learners and to give them choices about their interactions in the target language. As a result, they are no longer unfamiliar with the range of pragmatic devices and practices in the target language (Bardovi-Harlig \& Mahan-Taylor, 2009). Kasper (1997) suggested that pedagogical intervention on learners has the following aims: (1) to awaken the pragmatic knowledge of learners. It is necessary because they already have pragmatic knowledge of the first language; (2) To motivate learners to use their pragmatic knowledge of the target language in different contexts.

\subsection{Materials for Teaching the Pragmatics}

When designing teaching materials, there are three aspects to consider: social context, functional use of the target language, and interaction (Taguchi, 2011). Through these three aspects, learners know strategies and linguistic units (forms) that can be realized in speech acts. They also know how to use these strategies in different contexts.

Kasper (1997) then called components in pragmatics that are taught to learners: (1) discourse markers and discourse strategies, (2) pragmatic routine, (3) special speech acts, such as utterances, compliment, apology, rejection, welcome, or grievance (4) politeness, and (5) implicature. It would be better if the utterances given in the classroom were authentic utterances. These can be obtained by recording a telephone call, television disputes, films, electronic letters and the Internet (Bardovi-Harlig \& Mahan-Taylor, 2008). Learners should then interpret these utterances and engage in active exercises such as role play. The study by Jerniga (2012: 7) proved that the use of video in the classroom can increase intercultural pragmatics in English as a foreign language among the learners.

Cohen (2008) suggested that special speech acts are the main components in pragmatics that one has to teach in second or foreign language teaching. Cohen deals very intensively with the study of pragmatics. He has a special page on CARLA's website (The Center for 
Advanced Research on Language Acquisition) learning pragmatics. In this website (http://www.carla.umn.edu/speechacts/index.html) the special speech acts are in the foreground. We could then use this website as a model in the planning of pragmatics lessons.

\subsection{Strategies in Teaching the Pragmatics}

An important aspect of teaching is how to use pragmatics in class. For German teachers who teach German as a foreign language other than the German-speaking countries, their tasks are particularly difficult. They often find it difficult to find real social contexts in which learners can practice the learned speech acts. Teachers should be able to master the grammar and vocabulary of the target language well and be able to communicate appropriately in the target language. They also need to know the culture of the target language well and calculate the negative transfer from the learner's native language to the target language.

Roever (2009: 562) asked for a model for learning pragmatics

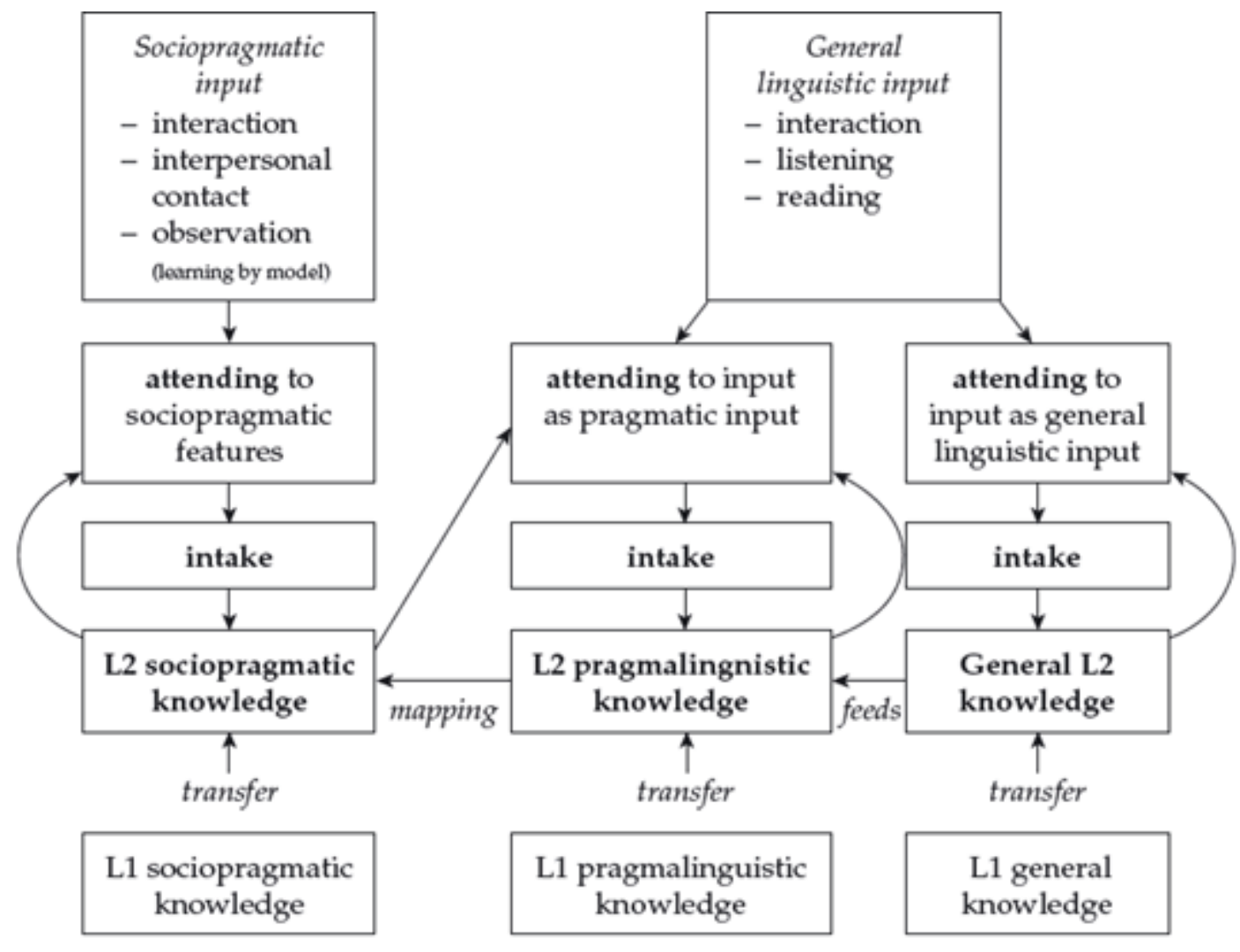

Figure 3. Pragmatic learning model

From this model it can be seen that two components in pragmatics (sociopragmatic and pragmalinguistics) are equally important. On the sociopragmatic side, learners must retain sociopragmatic characteristics based on the inputs they receive, such as the interlocutor's expression, the form of the relation, and the context. This process serves as a basis for the formation of knowledge about the relevant characteristics of the interlocutor and the influence of the context on language use. The sociopragmatic inputs can be obtained from personal contacts, interactions or observations. On the side of pragmalinguistics, learners retain pragmatic aspects of verbal input, such as using a modality and a question to express 
an indirect apology, as an alternative to declaratory expression. The inputs, which are closely related to the social context, are necessary for the formation of the pragmalinguistic knowledge of the learners. Therefore, learners should always try to identify such inputs. This knowledge is very useful to learners because they can take advantage of it if they are in an appropriate context. The teacher then has an important role in teaching learners to reconcile the two pragmatic components.

As mentioned before, the teachers have to pay attention to the negative transfer from the first language to the target language, because it can influence the development of knowledge about sociopragmatics, pragmalinguistics and language proficiency, especially among beginners. For the learners who are already advanced, the problem is relatively smaller. They transfer the pragmatic standards of the native language to the target language less in comparison to the beginners, because they are already able to control the target language $(\mathrm{Bu}, 2012)$

There are two popular teaching strategies related to pragmatics, namely explicit approach and implicit approach. In the explicit approach, the components in pragmatics are described and discussed by the teachers to complete the exercises and linguistic input. The second approach presents linguistic input and exercises, with no explanation of metapragmatic components (Kasper, 1997). According to Taguchi (2011: 291), the characteristics of pragmatics are explained directly by the explicit approach, and followed by the exercises. But with the implicit approach, these are direct explanation abolished, or at least postponed. Because of this, the learners only get linguistic input and opportunity to practice. Through the exercises, learners could then implicitly expand their knowledge of the pragmatic forms and how to use them appropriately.

Alternative tasks came from Taguchi (2011: 296). First task is consciousness-raising task. This task aims to increase the student's awareness. The learners listen to a dialogue and directly observe the pragmatic features and sociolinguistic variables of a particular speaking opportunity (eg, situation and the relationship between the speech partners). Another task is to practice the receptive skill. The learners deal with the pragmatic inputs. They must then evaluate the appropriateness of these pragmatic forms on the basis of the rating scale, or select appropriate forms from a list of expressions. Productive exercises are the next task. In these exercises, learners have to do role-playing games, make articulated conversations, or edit discourse completion test and cloze test.

Other strategy is by Martinez-Flor and Uso'-Juan (via Shively, 2010: 110). The strategy, which is based on the explicit approach, consists of 6 phases: researching, reflecting, receiving, reasoning, rehearsing and revising. This strategy is useful to learners in developing their pragmatic competence - as well as intercultural. In the first phase, learners are given explanations about pragmatics and special speech acts such as a request, apology and rejection. They then collect pragmatic data in their native language. In the second phase, the learners analyze this collected data under the direction of the teacher. This phase can sensitize learners' awareness of social factors and circumstances that influence pragmatic actions. In the third phase, students are given an explicit explanation of how to implement pragmatic elements in the target language. For example, the learners are given possible strategies with which they can produce the speech act of a request in the target language and compare it with the speech act in the native language. In the next phase (Rehearsing) the students analyze pragmatic data in the target language. They also identify social and situational factors as well as intentions of the speaker. This makes learners more sensitive (aware) for pragmatic elements in the target language. In the fifth phase, learners practice their pragmatic skills in 
communicative exercises, from guided exercises to more free exercises. In the final phase, learners receive feedback from the teacher and further guidance to develop their pragmatic ability in communicative actions.

\section{Conclusion}

Pragmatics as a branch of linguistics is currently an undisguised part of teaching German as a foreign language. The pragmatic aspect is an important part of the communicative approach. This approach was a response to the previous methods and approaches that emphasize the mastery of grammar, but do not take into account the sociocultural aspects, such as Grammar translation method. Hymes felt that language learning not only requires grammar and vocabulary, but also the appropriateness of an utterance with the socio-cultural context. For this reason, it is necessary that pragmatics is used in teaching German as a foreign language. There are two reasons for this. The use of pragmatics helps learners: (1) recognize the social and interpersonal aspects in a speaking opportunity so that they formulate appropriate utterances; (2) to avoid pragmatic failures as they conduct communicative action.

There are two areas of pragmatics that must be considered when planning and designing foreign language courses, namely pragmalinguistics and sociopragmatic. The materials taught in relation to the formation of pragmatic competence include special speech acts, implicature, politeness, routine formalities, and discourse markers and strategies. They can then be used in class through various strategies. The known approaches are explicit and implicit approach. Through the explicit approach, learners are given explicit explanations about the pragmatic features and norms. Then they do exercises. In contrast, learners do not get explanations in the implicit approach. They receive the pragmatic input and then deal with the exercises. These two approaches can be used alternately. The explicit approach is suitable for beginners. As their language ability gradually increases, one may use the implicit approach.

Another strategy is called 6R (researching, reflecting, receiving, reasoning, rehearsing and revising). This strategy includes awareness of pragmatic concepts, language input in the first language and target language, exercises in communicative actions, and feedback from teachers.

\section{References}

Bardovi-Harlig, Kathleen. 2005. On the Role of Formulas in the Acquisition of L2 Pragmatics. Indiana University.

Bardovi-Harlig, Kathleen, und Mahan-Taylor, Rebecca. 2009. "Introduction" in Teaching Pragmatics.

Chen, Yuanshan. 2009. "Learner Perceptions of Instruction in L2 Pragmatics" in English Language Teaching. Vol. 2, No. 4 Desember 2009.

Cohen, Andrew D. 2008. "Teaching and Assesing L2 Pragmatics: What can we expect from learners?" in Language Teaching, 41:2, pp. 213 - 235.

Jerniga, Justin. 2012. "Output and English as a Second Language Pragmatic Development: The Effectiveness of Output-focused Video-based Instruction” in English Language Learning Vol. 5, No. 4, April 2012. 
Kasper, G. 1997. Can pragmatic competence be taught? (NetWork \#6) [HTML document]. Honolulu: University of Hawai'i, Second Language Teaching \& Curriculum Center.

Purwo, Bambang Kaswanti. 1990. Pragmatik dan Pengajaran Bahasa, Menyibak Kurikulum 1984. Yogyakarta: Penerbit Kanisius.

Richards, Jack C., Schmidt, Richard. 2002. Longman Dictionary of Language Teaching and Applied Linguistics. London: Pearson Education Limited.

Roever, Carsten. 2009. "Teaching and Testing Pragmatics" in Handbook of Language Teaching. West-Sussex: Blackwell Publishing Limited.

Taguchi, Naoko. 2011. "Teaching Pragmatics: Trends and Issues" in Annual Review of Applied Linguistics (2011). 31, 289 - 310. Cambridge: Cambridge University Press. 